\title{
Tráfico de mulheres e exploração sexual: análise sobre o atendimento às vítimas
}

\author{
Tatiana Raulino de Sousa \\ Universidade Federal de Campina Grande (UFCG)
}

Tráfico de mulheres e exploração sexual: análise sobre o atendimento às vítimas

Resumo: Este artigo propõe reflexões acerca da atuação do Estado frente à dinâmica do tráfico de mulheres para fins de exploração sexual. A opção pela abordagem qualitativa se deu devido aos objetivos da pesquisa, o que possibilitou a análise do movimento do real, a partir dos diálogos estabelecidos com determinados sujeitos. Foram realizadas entrevistas individuais com profissionais que atuam na execução da política pública de enfrentamento à referida modalidade de tráfico no Estado do Ceará. O debate problematiza, além das questões de ordem estrutural e social da divisão da sociedade de classes, os aspectos políticos e culturais que permeiam o universo do tráfico de seres humanos.

Palavras-chave: Tráfico de mulheres. Exploração sexual. Políticas públicas.

\section{Trafficking of women and sexual exploitation: an analysis about attending to victims}

Abstract; This article offers reflections about the action of the state in relation to the trafficking of women for purposes of sexual exploitation. A qualitative approach was taken due to the research objectives, and allowed analysis of the movements of the real, based on dialogs established with certain subjects. Individual interviews were conducted with professionals who work in the execution of public policy to face this modality of trafficking in Ceará state. The debate problematizes, in addition to questions of a structural and social order of the division of society of classes, the political and cultural aspects that permeate the universe of human trafficking.

Keywords: Trafficking women. Sexual exploitation. Public policies. 


\section{Introdução}

O tráfico de mulheres no Brasil tem assumido dimensões alarmantes e complexas, possuindo estreitas relações com a dinâmica da acumulação capitalista contemporânea. Essa realidade, traduzida em um nível de expansão do mercado jamais vista, dada a nova configuração econômica mundial, possibilitou a transformação das mulheres, de histórico objeto de prazer masculino à condição de valiosa mercadoria, e também dinamizou atividades diversas, como é o caso do turismo, nas quais elas passaram a ser de suma importância no "pacote". Esse modelo de organização de sociedade - articulado em torno da produção da riqueza social para poucos, o que é possível somente pela exploração do trabalho da maioria da população - desenvolveu-se a partir da tendência imanente à sociedade burguesa de transformar tudo e todos/as em objetos, com vistas a auferir mais lucros, submetendo o conjunto da vida social à sua lógica destrutiva e desumana. Isso significa destituir a humanidade de alguns dos seus valores mais caros, como a liberdade, a autonomia e a dignidade, e ainda lhe fazer perder o controle sobre seu corpo.

O tráfico de pessoas tem se tornado uma das preocupações centrais na contemporaneidade, sendo esse tema inserido no cotidiano da sociedade de forma mais incisiva nos últimos anos e se impondo como pauta importante demandada às políticas públicas governamentais especialmente após a assinatura do Protocolo Adicional à Convenção das Nações Unidas contra o Crime Organizado Transnacional, relativo à Prevenção, Repressão e Punição do Tráfico de Pessoas, em especial mulheres e crianças, conhecido como Protocolo de Palermo, ratificado pelo governo brasileiro em 2004. Nesse sentido, o Brasil também se comprometeu em seguir as recomendações internacionais de enfrentamento ao tráfico de pessoas e àquelas relativas a todas as formas de exploração e violência, a exemplo das recomendações do Comitê Supervisor da Convenção sobre a Eliminação de todas as Formas de Discriminação contra as Mulheres (Cedaw) e da Convenção Interamericana para Prevenir, Punir e Erradicar a Violência contra a Mulher, "Convenção de Belém do Pará", de 1994. Na perspectiva de atender as deliberações internacionais no tocante ao tráfico de pessoas, instituiu-se em 2006 no Brasil o Grupo de Trabalho Interministerial para estabelecer as prioridades de ação do I Plano Nacional de Enfrentamento ao Tráfico de Pessoas (PNETP) dentro dos eixos temáticos determinados pela política nacional. No que tange às ações voltadas para as mulheres, o II Plano Nacional de Políticas para as Mulheres (PNPM), em 2008, referendou a perspectiva daquela política. A criação de Núcleos de Enfrentamento ao Tráfico de Pessoas nos Estados e a implantação dos postos avançados de atendimento em diversos aeroportos do País deu capilaridade às ações da política nacional, estando, inclusive, na pauta de avaliação das estratégias de ação para o desenvolvimento do II PNETP, com audiências públicas em diversos Estados, inclusive no Ceará, culminando em sua recente aprovação.

A política nacional, no tocante ao atendimento às pessoas em situação de tráfico, tem como proposta viabilizar a construção de uma prática institucional capaz de fortalecer política e socialmente os sujeitos explorados, tendo como estratégia fundamental a articulação entre diversas políticas e setores. Por essa razão, percebemos a relevância de estudos e pesquisas em perceber como a Política Nacional de Enfrentamento ao Tráfico de Pessoas está sendo materializada nos Estados, considerando suas especificidades socioeconômicas e culturais. O interesse pela temática surge das nossas ações por ocasião de representação na Unidade Temática Gênero e Municípios da Rede Mercocidades, o que possibilitou o conhecimento da experiência governamental na América Latina. Assim, a militância no movimento de mulheres e as ocasiões de formação/representação em eventos nacionais e internacionais voltados para o enfrentamento ao tráfico de pessoas, foram fundantes para a materialidade da proposta em tela. Desse modo, buscamos analisar a atuação do Estado frente à problemática do tráfico de mulheres no Ceará, por meio do estudo das ações desenvolvidas pelo Núcleo de Enfrentamento ao Tráfico de Pessoas do Estado (NETP/CE). Pela especificidade do recorte nas mulheres em situação de tráfico para fins de exploração sexual comercial, consideramos pertinente identificar as concepções expressas pelas "operadoras" da políti-

O contexto que enraíza os problemas sociais vivenciados pelas mulheres em situação de tráfico de pessoas e migração irregular, está relacionado à precarização das relações de trabalho e à falta de políticas estatais efetivas. ca acerca dessa modalidade de tráfico, das ações desenvolvidas pelo NETP/CE e das principais dificuldades encontradas na execução da política. 


\section{Percurso metodológico ${ }^{1}$}

A pesquisa não ocorreu de forma isolada, focalizada ou fragmentada da totalidade social, mas no movimento dinâmico das relações sociais mais amplas, em suas múltiplas determinações, contradições, mediações e em suas expressões/implicações na realidade concreta. Consequentemente, a investigação fora orientada pela perspectiva de totalidade que possibilita a apreensão racional da realidade para além da aparência e da causalidade dos fenômenos, em suas íntimas conexões internas, nas quais se autodeterminam. Ir à contramão dessa perspectiva implica tornar estéril a riqueza da dialética do conhecimento. A investigação é de natureza qualitativa, posto que trabalhou com o "universo de significados, motivos, aspirações, crenças, valores e atitudes, o que corresponde a um espaço mais profundo das relações, dos processos e dos fenômenos que não podem ser reduzidos à operacionalização de variáveis" (MINAYO, 1993, p. 21-22). A pesquisa ocorreu no Núcleo de Enfrentamento ao Tráfico de Pessoas do Estado do Ceará (NETP/CE), vinculado à Secretaria da Justiça do Ceará, sendo realizadas entrevistas semiestruturadas com profissionais que atuam no referido núcleo.

O trabalho de campo articulou entrevistas, observações, levantamentos de material documental, bibliográfico, instrucional, entre outros. Paralelamente, participamos de atividades desenvolvidas pelo NETP/CE, o que favoreceu a construção da relação de conhecimento entre sujeito-objeto. Ademais, buscamos informações em relatórios e outros documentos disponibilizados pela coordenação do núcleo. Realizamos anotações em diário de campo, com o objetivo de resgatar as experiências vivenciadas e acumuladas durante o processo de inserção na dinâmica desse cotidiano.

Por fim, ocorreu a descrição, o tratamento e a análise dos dados coletados na pesquisa. Durante a análise, as questões foram agrupadas em tópicos específicos e interpretadas considerando as falas comuns e divergentes apresentadas pelas interlocutoras da pesquisa, ou seja, comparando e confrontando posições, extraindo significados das falas e registros, além de realçar os ditos e os nãos ditos. Para atender à garantia do sigilo das interlocutoras, utilizamos, para a apresentação de trechos dos depoimentos, nomes fictícios escolhidos entre as muitas feministas brasileiras. Dessa forma, independente de qualquer dimensão valorativa, identificando-as de acordo com a nomenclatura da feminista, sem fazermos qualquer associação de personalidade ou moral.

\section{A política de atendimento no Ceará: (in)compreensões no trabalho profissional}

O contexto das contradições entre a proposta apresentada pela Política Nacional de Enfrentamento ao Tráfico de Pessoas (PNETP) $)^{2}$ e sua operacionalização pelas instituições responsáveis é o terreno que a presente pesquisa buscou analisar. Centra-se na atuação do Estado, na prevenção e assistência às mulheres em situação de tráfico através das ações desenvolvidas pelo Núcleo de Enfrentamento ao Tráfico de Pessoas do Estado do Ceará (NETP/CE) $)^{3}$, tendo como referência os relatos das profissionais que trabalham na instituição.

Todas as interlocutoras revelaram não ter nenhuma experiência de trabalho com a temática anteriormente. Contudo, há quem tenha mencionado prévios estudos acadêmicos sobre o tráfico de pessoas e também algumas aproximações com debates na área de direitos humanos e/ou políticas públicas. No entanto, segundo os relatos, a partir do ingresso na instituição, elas têm buscado formação continuada, individual e/ou coletivamente, para além dos materiais institucionais disponibilizados, conforme evidenciamos nas falas de profissionais:

Fomos estudando pelo material que vinha de Brasília, pela internet, buscando nos apropriar das legislações internacionais, além daquilo que vinha de outros Estados do Brasil. Assim, posso afirmar que nosso conhecimento foi construído por um esforço individual, por vezes coletivo (PAGU).

Eu não tinha conhecimento nessa temática antes de vir pra cá. Aqui, fazemos estudos dos materiais científicos que chegam, bem como dos trabalhos científicos, artigos, além da internet, já eventos sobre a temática são poucos os eventos relacionados à temática são muito poucos, [...] é importante destacar a nossa elevada demanda de trabalho que, por vezes, inviabiliza esses momentos de estudos e debates entre a gente (LUZDELFUEGO).

Reunimo-nos para estudo de caso, além daqueles que os outros núcleos e postos compartilham conosco (NÍSIAFLORESTA).

As entrevistadas também mencionam a dificuldade de participar de formação continuada devido ao número restrito em que ocorrem, bem como o formato destas: 
A participação nos eventos de formação e capacitação é muito incipiente. Sentimos essa necessidade, mas a oferta ainda é bastante escassa (LÉLIA GONZÁLES).

Como dificilmente temos acesso às capacitações realizadas pelo Ministério da Justiça, era interessante que ocorressem por videoconferência ou mesmo pela internet, enfim de uma forma que tivéssemos possibilidade de acesso, ainda que não fosse o ideal (NÍSIA FLORESTA).

As capacitações são restritas. Os encontros sempre são direcionados aos gestores. Ainda que ocorra a socialização do debate travado nestes, não é a mesma coisa, até pelas nossas demandas diárias. Sinto necessidade de debater, dialogar, discutir com as profissionais que trabalham na execução da política, assim como a gente (BERTHA LUZ).

As falas apontam as barreiras no acesso às capacitações que implicam no processo de formação continuada para o exercício profissional junto ao tráfico de pessoas. É importante destacarmos que, apesar da aprovação da política e de já estarmos na vigência do segundo plano, as oportunidades de discussão sobre a temática ainda são restritas, inclusive para aquelas que estão diretamente na operacionalização da política, o que, em nossas análises, rebate diretamente na qualidade dos serviços prestados, obviamente, numa análise distante de culpabilizar o sujeito pelo não acesso às discussões mais amplas. Apesar da restrição no debate dialético, via encontro e formação, é importante destacar que um dos sujeitos da pesquisa revelou avanço, a partir da articulação da Rede de Núcleos e $\operatorname{Postos}^{4}$, no tocante à padronização de instrumentais, socialização de experiências e visitas institucionais:

A criação da rede de núcleo e postos é um divisor de águas, pois trouxe a possibilidade de um fluxo, sistematização, etc [...] Antes, o trabalho ficava muito na dimensão do senso comum, pois as equipes desenvolviam suas ações muito a partir do que achavam que "conheciam" sobre o tráfico de pessoas, a partir das vivências do trabalho cotidiano, sem pensar de forma crítico e mesmo a necessidade de um trabalho articulado. Hoje, apesar da autonomia e das especificidades regionais, a portaria da SNJ, por exemplo, estabelece o que é competência do núcleo ou do posto (NÍSIA FLORESTA).

Para tanto, a Secretaria Nacional de Justiça (SNJ), por meio da Rede de Núcleos e Postos, contratou consultorias para acompanhamento das atividades de prevenção e enfrentamento ao tráfico de pessoas, construção de instrumentais e fluxos e articulação da rede e dos comitês estaduais, respeitadas as especificidades regionais, conforme evidencia uma das interlocutoras:

Recentemente, também, recebemos outra consultoria do mesmo projeto pra tentar articular e pactuar os nossos fluxos de atendimento e referências, são fluxos que estão sendo discutidos em nível nacional. É claro que os Estados podem adaptar de acordo com a realidade local, não é uma coisa que seja estanque e que a SNJ empurra pra que todos os núcleos possam cumprir, mas é uma coisa que está sendo construída também em nível nacional até pra que o documento seja um documento rico e possa contemplar as nossas especificidades (NÍSIA FLORESTA).

Tal processo fora articulado a partir das demandas registradas na avaliação do I PNETP. Assim, foram discutidas e agrupadas as questões pertinentes aos encaminhamentos distintos entre os núcleos, ausência de fluxo da rede nacional e necessidade de construção de redes locais, tendo os comitês estaduais como espaço privilegiado de discussão de acompanhamento e interface da política. Com isso, buscamos compreender como ocorrem as ações profissionais desenvolvidas no NETP/CE, ainda que os discursos fossem unânimes ao relatarem os processos de atendimentos às vítimas e encaminhamentos, articulação institucional (intra e extra), relatórios, atividades internas e externas (campanhas, palestras e formações):

Recebemos as denúncias, acolhemos as famílias, geralmente presentes no primeiro contato com as vítimas. Os encaminhamentos sãos os mais diversos, a depender da demanda que o sujeito apresenta, que vão desde abrigo até para Centro de Atenção Psicossocial (Caps), cursos profissionalizantes, entre outros. Além disso, ainda elaboramos os relatórios, encaminhamentos das denúncias para os órgãos competentes e responsáveis (LÉLIA GONZÁLES).

Ministramos cursos de formação, capacitações em escolas e hotéis, além das ações de prevenção nas barracas de praia, afixamos material informativo (LUZ DEL FUEGO). 
Em todas as falas, há destaque para as atividades de prevenção, provavelmente pela necessidade de redefinição das atribuições do NETP/CE, após a publicação das Portarias 31/2009 e 41/2009, que respectivamente demarcam os objetivos dos núcleos e altera o caráter repressivo dos escritórios. Também destacaram que a priorização das atividades preventivas, principalmente por meio da interiorização das ações, é resultado do planejamento anual do NETP/CE, sendo avaliado nos encontros e reuniões:

Na verdade, nós tivemos uma reunião de planejamento anual, com a nossa dinâmica muitas vezes não dá nem pra fazer a reunião mensal. Tivemos uma agora recentemente, mas tem meses que, por conta da dinâmica das viagens, das atividades de interiorização isso fica comprometido (BERTHA LUZ).

Reunião de planejamento teve uma no começo do ano, quando a gente fez todo o planejamento anual das ações que seriam desenvolvidas, já marcando na agenda todas as datas, dentro de um orçamento que é bem complicado (LÉLIA GONZÁLES).

Nessas reuniões, aproveitamos, também, para avaliar nossas ações. Devido a distância entre elas, por questões diversas, apesar de termos os fluxos, não sabemos se estamos pautando nossas ações em consonância com o previsto na política (PAGU).

Sobre os instrumentais, as entrevistas apontam que, organizados como estão, é uma situação bem recente e resultam do esforço da equipe do NETP/CE para sua construção. Segundo as entrevistas, foram elaborados a partir da leitura de matérias que conseguiram pela internet ou referenciados pelo Ministério da Justiça:

Fomos construindo os instrumentais, pois no começo não tínhamos nenhuma orientação, daí fazíamos os relatórios e as informações eram, muitas vezes, perdidas. Hoje, posterior às atividades desenvolvidas, elaboramos um relatório (PAGU).

Em todos os casos são abertos processos, realizada a identificação, gerado relatório, feito os devidos encaminhamentos, ocorre o arquivamento. A escuta, na maioria das vezes, para que a pessoa não precise repetir várias vezes a mesma estória, é feita por mais de uma profissional (BERTHALUZ).

Além de percebermos a rotina e fluxo e institucionais, a análise sobre a importância dos registros, arquivos e encaminhamentos é importante porque, em se tratando de cargos em comissões e/ou contratações terceirizadas, existe uma grande rotatividade nas instituições públicas, e o NETP/CE não foge a essa regra. Ademais, com o registro das atividades, para além da memória, é possível acompanhar os casos, e evita que as mulheres em acompanhamento precisem contar sua história sempre que acionem o serviço. Infelizmente, dentro das muitas formas de violência que vivenciaram, por vezes, a repetição da socialização destas acaba por se constituir em mais uma. Adentrando a essência desta proposta investigativa, dialogamos com as interlocutoras da pesquisa sobre suas concepções da temática que trata do tráfico de mulheres para fins de exploração sexual comercial:

Eu digo inicialmente que é real, aí eu vislumbro o alojamento, o abuso da força, a situação de vulnerabilidade, tudo de acordo com a nossa experiência na questão do tráfico de mulheres [...] uma realidade difícil porque existem essas propostas, esses aliciamentos, esse transporte, esse alojamento, e hoje consigo vislumbrar esse conceito de tráfico, lembrando realmente das situações que eu acompanho com a questão do abuso, da ameaça, da força e da situação de vulnerabilidade (NÍSIA FLORESTA).

O tráfico para exploração sexual, a meu ver, é uma mulher, ou travestis, que são deslocadas do local onde elas moram e convencidas de alguma maneira a ir para outro município, Estado ou país, para trabalharem numa determinada situação que elas acham que vai ser boa pra elas, porque nenhuma pessoa vai achando que vai ser ruim. Quando chega lá, ela realmente se depara com outra realidade, ou seja, porque ela ficou impedida de sair de um ambiente, ou porque ela está ganhando menos do que prometeram e que ela está sendo violada na proposta que recebeu inicialmente (PAGU).

Alguns/mas autores/as advertem que esse "consentimento" não pode interferir na caracterização do crime, pois, na maioria das vezes, a vítima sabe que irá realizar programas sexuais, mas não imagina em que condições irão fazê-los. Nesse sentido, Kempadoo (2005, p. 63-64) revela que: 
mulheres e meninas tentam mudar para o exterior consciente e voluntariamente para melhorar suas vidas e as de suas famílias. O que essas mulheres muitas vezes não sabem, ou às vezes aceitam tacitamente, são os perigos das rotas subterrâneas que têm que usar para atravessar a fronteira, os custos financeiros, o tipo de atividades, as condições de vida e de trabalho na chegada, o alto nível de dependência de um conjunto específico de recrutadores, agentes ou empregadores, os riscos de saúde, a duração do emprego, seu status criminoso no exterior, a violência e/ou períodos de detenção ou encarceramento que poderão ter que enfrentar.

Assim, considerável quantitativo de mulheres que estiveram inseridas em contexto de pobreza e discriminação no local onde foram aliciadas, emana consentimento que deve ser interpretado na perspectiva da indução, haja vista a oportunidade de trabalho, seja no exterior ou em outras localidades ao redor do País, o que desponta para elas como possibilidade de melhoria na qualidade de vida. Uma questão difícil nesse sentido envolve a dificuldade, por vezes, de as mulheres reconhecerem que estiveram em situação de tráfico de pessoas, existindo a autorresponsabilização pelos problemas que elas vivenciaram.

O tráfico de mulheres para fins de exploração sexual comercial é a principal modalidade do tráfico de pessoas praticada no Estado do Ceará, não diferentemente, o maior número de denúncias que chegam ao NETP/CE corresponde a esse tipo de crime. Nossas interlocutoras confirmam essa informação, quando uma delas revela que "é uma das modalidades do tráfico que a gente mais vê aqui na nossa cidade. Pelo menos aqui em Fortaleza, das nossas denúncias, a maioria é de tráfico pra fins de exploração sexual” (PAGU). Em nossas análises, percebemos uma nítida relação entre exploração sexual e o turismo, principalmente pela localização e atributos geográficos do Estado do Ceará, para além das expressões da questão social presentes historicamente no nordeste brasileiro:

A questão da situação sexual que acontece no turismo tem vitimizado as mulheres e meninas em nosso Estado. Envolvem rede hoteleira, os 'bugueiros', os taxistas. Nós já realizamos trabalho com os hotéis, com os taxistas, enfim, mas não se pode negar esse problema aqui no Ceará, por mais que a gente dialogue com a Secretaria de Turismo (Setur) no Comitê de Enfrentamento ${ }^{5}$ e eles tenham essas dificuldades de reconhecer pra incentivar ou não. É uma realidade, sim, porque nós recebemos denúncias aqui. Recebemos, em Aracati, quando estivemos lá e acredito que vamos receber ainda mais porque estaremos juntos com o projeto do Pair ${ }^{6}$ nos municípios do litoral do Estado. [...] Reconhecemos sim essa ligação da exploração sexual que acontece no turismo pelas denúncias que o posto recebe (NÍSIA FLORESTA).

Os elementos destacados sobre a dificuldade dos órgãos ligados ao turismo reconhecerem o problema da exploração sexual é uma realidade. Tivemos a oportunidade de participar do Conselho Municipal de Turismo de Fortaleza e sentimos a resistência de abordar essa temática quando, por diversas vezes, a apresentação dos projetos em desenvolvimento junto à problemática foi preterida. Além disso, os representantes do trade turístico do Ceará, na sua quase totalidade, não reconhecem a exploração sexual relacionada às mulheres adultas. Além de compreender sobre a dinâmica do atendimento às mulheres em situação de tráfico para fins de exploração pelo Estado, procuramos também descortinar como a demanda chega ao NETP/CE, o que podemos compreender por meio das falas de nossas interlocutoras:

Geralmente é pelo telefone lá da recepção. A pessoa liga e aí relata que quer fazer uma denúncia. No caso de ser anônima, o apoio administrativo chama alguma das técnicas pra receber a denúncia. Daí é feito um relatório da denúncia e é encaminhada para a coordenação com algumas sugestões de fluxos. Mas é a coordenação que decide e despacha pra onde vai, assim como também os ofícios que vão ser enviados referentes àqueles casos. Quando não é anônimo, quando a família ou a vítima está disposta a vir, o apoio administrativo também marca um horário em que sempre as técnicas vão estar, pra fazer o acolhimento inicial e a escuta também (LÉLIA GONZÁLES).

Tem alguns casos que chegam encaminhados de outras instituições, às vezes da própria polícia ou de um Creas ou Cras. Mas, a maioria é de ligações anônimas ou pelo meio de virtual ${ }^{7}$, que foi instituído agora (LUZ DELFUEGO).

Recebemos aquela demanda espontânea. Então, por exemplo, hoje nós temos um diálogo muito bom com o Centro de Referência da Mulher, quando chega um possível caso de tráfico elas já entram em contato e nós fazemos o atendimento conjunto. Eles já sabem que o núcleo existe e já sabe que tem os profissionais com um pouquinho mais de expertise. Então, é possível acontecer esse atendimento conjunto, ou aqui ou lá, ou 
somente pelo núcleo, depende dessa parceria. Então, tudo depende do diálogo que nós temos com esse ente, ou esse órgão, ou essa ONG que está encaminhando essa possível denúncia (NÍSIA FLORESTA).

A gente recebe a denúncia, abre um processo interno, têm as pastas onde anotamos como foi relatada, se foi anônima ou não, tem um modelo no relatório. A gente anota as informações que recebeu, aí vai estudar. Aquela denúncia se refere a quê? Ao tráfico internacional? E, então, a gente encaminha para a Polícia Federal, inicialmente. Refere-se a um possível trabalho escravo? Nessa situação, além da Polícia Federal, encaminha-se também para o Ministério do Trabalho, que são instituições que a gente tem parceria (PAGU).

Percebemos a existência de instrumentais internos para monitoramento das denúncias e encaminhamentos padrões junto à rede de instituições responsáveis pelo acompanhamento, de acordo com a demanda e modalidade do tráfico de pessoas. Embora a articulação com as polícias, na maioria das vezes, precise acontecer, parece-nos que não são dados os retornos necessários para melhor acompanhamento do NETP/CE às vítimas. Apesar disso, visualizamos que a organização do fluxo interno, encaminhamentos externos, ainda que com todas as suas dificuldades de retornos e articulação da rede de enfrentamento, são imprescindíveis à rotina de trabalho das profissionais. Consideramos essas ações oportunas, sobretudo porque entendemos que a atenção às vítimas do tráfico de pessoas requer articulação da rede.

No concernente a rede local, procuramos obter mais informações sobre as articulações, mais especificamente sobre as instituições parceiras e a formalidade do vínculo:

Hoje não temos nenhuma parceria formal em nível de convênio, firmado e assinado. Mas nós temos parceria com algumas ONGs, a Polícia Federal, as escolas, a gente considera, no caso, a Secretaria de Educação, que a gente tem uma articulação, mas nada formal (PAGU).

Além das ONGs, temos as articulações na educação, mas depende da boa vontade dos diretores e coordenadores para realizarmos nossas ações (NÍSIA FLORESTA).

Dependendo da instituição, a gente tenta estipular um termo de cooperação técnica, outros, com o tempo nós percebemos a importância de agregar parceiros no comitê, a Infraero, a Superintendência Regional do Trabalho, que é a antiga Delegacia do Trabalho, a Cruz Vermelha está conosco nessa questão da cesta básica para casos especiais (BERTHA LUZ).

Podemos perceber que a maior parte das relações ainda acontece informalmente, sem parcerias e convênio oficiais, com parcos fluxos e protocolos estabelecidos. Isso nos remonta às características da base da nossa política e do desenvolvimento das políticas públicas, as relações por aproximação, "boa vontade", favores, etc. Avaliamos com muita preocupação essa realidade, principalmente quando se trata de políticas públicas que, como é o caso da atenção às mulheres em situação de tráfico para fins de exploração sexual comercial, envolvem muitas questões de valores morais, culturais e preconceitos agregados. A insatisfação, desse contexto, fora evidenciada por uma das profissionais entrevistas.

Realizamos uma verdadeira peregrinação, batendo de porta em porta porque nós acreditamos no trabalho. Mas, existe um comitê pra isso, para que esse trabalho seja fortalecido, seja um trabalho efetivamente executado. O comitê existe? Existe. Tem titular? Tem. Acho que cada um assumiu seu compromisso, cada instituição entendeu. Então, a gente fica se questionando, questiona muito o comitê porque tudo poderia ser muito mais institucional. [...] eu imaginava, pensava que com essa criação do comitê fosse facilitar mais ainda o nosso trabalho, as coisas fossem articuladas, que ia ser tudo mais institucional, mas na hora da situação todo mundo foge. [...] a gente realiza os encaminhamentos, não tem retorno: 'aguarda só mais um pouco, não tem resposta'. Então, assegurar todos os serviços pra que a pessoa possa se sentir fortalecida, pra que ela possa ser reinserida na sociedade, é muito difícil. Eu acho que pra garantir tudo isso tem que existir uma rede e que essa rede funcione efetivamente (BERTHA LUZ).

Ainda sobre os parceiros, foi destacada a atuação do Comitê como mediador importante das relações institucionais com a rede governamental e a participação direta de alguns órgãos em atividades específicas.

Eu consideraria os parceiros, os órgãos que compõem o comitê. O comitê interinstitucional é composto de quem a gente sempre recorre: é a Secretaria de Educação, a Secretaria de Saúde, Polícia Federal, Ministério do Trabalho, Defensoria Estadual, enfim, diversos órgãos que compõem. Se essa parceria é formal, eu 
acredito que sim por conta do decreto que coloca lá todos os órgãos que compõem. Mas já sobre fluxo e protocolos estabelecidos com eles, não. Não há nada especifico em relação a isso (LÉLIA GONZÁLES).

Não posso dizer que não temos o apoio da Secretaria de Educação do Estado, porque ela está no comitê, mas isso depende também da capacitação e da sensibilização do gestor que está lá no momento, que está a fim de me receber (NÍSIA FLORESTA).

Estamos tentando articular uma parceria com os postos de saúde. É interessante porque os agentes de saúde têm muito acesso às casas, aos $\mathrm{PSFs}^{8}$, então, estamos avaliando se conseguimos conversar mais com eles. Esses profissionais podem relatar alguma coisa e podem até levar as informações que julgarmos necessárias. No entanto, as coisas ainda acontecem muito na lógica do favor, o pior é que assume uma dimensão para o lado pessoal. Ora, caso os processos fossem institucionalizados, tudo poderia ser bem diferente (PAGU).

A constituição do Comitê Estadual Interinstitucional de Enfrentamento ao Tráfico de Pessoas em 2011, correspondendo à proposta nacional, gerou expectativas no que diz respeito à maior inserção e capilaridade das ações desenvolvidas pelo NETP/CE, a elaboração do Plano Estadual de Enfrentamento ao Tráfico de Pessoas e efetivação da política. Contudo, mesmo com a minuta dos documentos preparados e disponíveis para consulta pública, no que tange mais diretamente à mobilização para as ações específicas de prevenção e atenção às vítimas, infelizmente não percebemos ainda grandes avanços.

Com relação ao atendimento e/ou encaminhamento por ocasião de identificação de vítima do tráfico para fins de exploração sexual, as interlocutoras fizeram as seguintes revelações:

O encaminhamento é feito similar ao de uma pessoa que não está em situação de exploração sexual ou não atuasse como prostituta. Eu não me recordo de nenhum procedimento especial, é oficiado do mesmo modo pra polícia, é oficiado da mesma forma aos órgãos de inteligência pra identificar os aliciadores, são encaminhadas da mesma forma pra reinserção no mercado de trabalho, e aí vai ficar a cargo delas se inserir ou não em outra atividade (LUZ DEL FUEGO).

É aquela velha história, é muito difícil a vítima de tráfico se reconhecer enquanto vítima. Às vezes os familiares não sabem o que aconteceu e não querem que a vizinhança fique sabendo da que ela foi explorada sexualmente, enfim, é bem complicado. Isso aí também, talvez, dificulte nosso atendimento/encaminhamento (LÉLIA GONZÁLES).

Os encaminhamentos são feitos independente pra que tipo de finalidade. Agora, como a maioria dos casos é pra exploração sexual, então se torna o procedimento comum do núcleo. A gente tenta resguardar ao máximo a pessoa, acompanha em todos os encaminhamentos. A gente fica acompanhando até o momento que ela é inserida no serviço, aí depois a gente tenta fazer o acompanhamento, ligando pra saber como é que está, fazendo as visitas eventuais (PAGU).

Segundo as profissionais, de forma geral não existe atendimento diferenciado às mulheres vítimas do tráfico para fins de exploração sexual comercial. No entanto, todas mencionaram dificuldades de atendimento na rede ou para tratar sobre a temática, como bem revela uma das interlocutoras.

Na hora de referenciar, a rede não se reconhece enquanto rede de enfrentamento ao tráfico de pessoas e principalmente ao tráfico de mulheres, a exploração sexual e o casamento servil principalmente. Então, claro que nós tentamos evitar aquela revitimização, fazemos um relatório com as informações relevantes pra que ela não repita em todos os espaços aquela história de vida. Às vezes, tem que repetir na Polícia Federal, na Polícia Civil [...] Às vezes, a gente vai pra um Caps e o profissional não ouviu sobre o tráfico de pessoas, a importância daquele sujeito ter um atendimento mais diferenciado porque ela está com medo de passar por um processo de adoecimento devido a situação vivenciada, onde, em algumas situações, ela foi obrigada a consumir drogas, foi explorada: "E vai pro final da fila, não quero saber, não tem prioridade nenhuma", é uma das nossas dificuldades. [...] os preconceitos pela questão do gênero são potencializados, pelo fato de ser mulher e a relação com a situação de prostituição (NÍSIA FLORESTA).

A fala da profissional demarca que o tráfico de mulheres para fins de exploração sexual, embora seja o mais pesquisado e discutido, em nosso ver é ainda o que requer mais investida e discussões. Principalmente, 
por adentrar no universo da sexualidade das mulheres, nas históricas relações de dominação masculina e da mercantilização do corpo das mulheres, prescinde análises despidas dos preconceitos e do véu machista que as envolve. No que se refere aos abrigamentos, foi unânime entre as entrevistadas as dificuldades para conseguilo, precisando usar das mais diversas estratégias para garantir um acolhimento seguro às mulheres:

A vítima deveria ter o direito de ser resguardada em primeiro plano, a segurança nesse momento é fundamental. Eu acredito que ela deveria ser mais acolhida pela rede, uma das nossas dificuldades é o abrigamento (BERTHALUZ).

As pessoas perguntam se não tem um abrigo específico. Nós procuramos parcerias nos abrigos que já existem, que não têm um viés especifico, mas que acabam colaborando e se reconhecendo enquanto rede nesse momento. Depois de muito diálogo, muita conversa, mas acabam se reconhecendo. Não existe uma rede e depende muito do perfil da vítima (NÍSIA FLORESTA).

A maior dificuldade que a gente tem é quando precisa de abrigamento. O Estado e o Município têm poucos locais adequados pra mulheres vítimas de tráfico e que foram exploradas. Quando tem, estão lotados. Quando é um caso que precise de recâmbio, a pessoa chega aqui, não é daqui, tá aqui por algum motivo e está sendo atendida pela gente, mas é do Piauí ou de Rondônia ou do Acre. Esse recâmbio é dificultoso (LUZDELFUEGO).

A questão do abrigamento tem se constituído como um problema para as políticas de atenção. Em Fortaleza, cidade onde o NETP/CE está localizado, temos apenas duas casas para abrigo de mulheres em situação de violência doméstica e sexual que têm perfis diferenciados de atendimento e que, por tratarem do risco de morte, apresentam diversas restrições para acesso e trânsito. Os demais espaços são abrigos mistos que atendem população em situação de rua, desabrigados/as etc. Esse é um dos graves problemas a serem enfrentados e, quando associado à situação de "recâmbio" ou necessidade de compra de passagens para outras cidades.

$\mathrm{Na}$ investigação em tela, também, buscamos compreender como funciona o NETP/CE, com ênfase no atendimento às suas demandas, procuramos investigar os recursos disponíveis para o desenvolvimento da política e a compreensão dessa dinâmica a partir das falas de nossas interlocutoras nesta pesquisa:

É a Coordenadoria de Cidadania (Cocid) que faz a distribuição desses recursos. Agora, eu não sei dizer como é, se vem o recurso direito pra Cocid, se é uma rubrica que vem direto da Cocid que vem pra gente, se é de cada setor, eu não sei. Tudo é pela Cocid, nesse momento todo o nosso trabalho é bancado pela Secretaria de Justiça do Estado (PAGU).

Todas as nossas demandas, os nossos custos a gente solicita pra cidadania. Em relação à política, como ela está no orçamento, é uma coisa que foge da minha alçada (LUZ DEL FUEGO).

Eu não sei se é exatamente da onde vem o fundo, se é da Cocid ou se é do NETP/CE. Mas a questão é que as demandas estão sendo atendidas, não sei se exatamente do "suprimento A", do "suprimento B" ou se do núcleo especifico, mas existe (NÍSIA FLORESTA).

A coordenação, que é a Cocid, está dentro do orçamento, então o recurso é passado pra essa coordenação e é redistribuído. Mais detalhes, eu não sei (BERTHA LUZ).

O que eu sei é que agora nós somos subordinadas à Cocid e ao gabinete, nós somos um membro da Cocid junto com alguns outros conselhos, do deficiente, de torturas e direitos humanos. Sempre que precisamos de alguma coisa, a gente recorre ou ao gabinete ou à Cocid, mas em relação a valores, de quanto é destinado eu não tenho nem ideia se tem isso (LÉLIA GONZÁLES).

Constatamos no que tange à gestão do orçamento, o desconhecimento das interlocutoras sobre valores, dotações, destinados à efetivação da política. Apenas têm ciência do lugar do NETP/CE dentro da estrutura da Secretaria da Justiça do Estado do Ceará. Esse ainda é um traço muito comum na administração pública, donde o orçamento das políticas públicas não é amplamente discutido, nem trabalhado com aquelas/es que cotidianamente estão na sua execução. Partimos da compreensão que a importância de determinada política dentro de uma gestão pública está relacionada ao orçamento disponível para o desenvolvimento de suas ações, assim como o lugar que ocupa dentro da estrutura e na pauta das prioridades. 
Assim, são muitos os desafios a serem enfrentados para uma efetiva atenção às mulheres em situação de tráfico de pessoas. Mesmo sem desconsiderar a responsabilidade individual dos sujeitos como seres ativos, avaliamos que, enquanto a Política Nacional de Enfrentamento ao Tráfico de Pessoas se não for efetivamente incorporada pelos governos estaduais e municipais, a atenção será parcial e não corresponderá às necessidades das vítimas. Também não podemos pensar na efetivação de políticas públicas adequadas para mulheres em situação de tráfico de pessoas e exploração sexual enquanto as estruturas do preconceito e discriminação perpassarem os horizontes daquelas/es que teriam, como gestor/a, a responsabilidade de zelar pela garantia de seus direitos. Precisamos, igualmente, de uma crítica capaz de perceber a totalidade social na qual se inserem as mulheres que vivenciam essa problemática, compreendendo as relações que permeiam o modo de produção capitalista em sua fase atual, sem perder de vista o caráter de organização do Estado e suas respostas, por meio das políticas públicas, às múltiplas expressões da questão social.

\section{Considerações finais}

Associado à histórica opressão da sexualidade das mulheres e mercantilização dos seus corpos, repitase, o problema do tráfico de pessoas no mundo, e de modo especial no Brasil e no Estado do Ceará, compreendemos que está relacionado à pobreza, desigualdade entre regiões, ausência de trabalho e salários dignos, ineficiência do Estado na execução de políticas públicas e proteção de direitos fundamentais e humanos.

O contexto que enraíza os problemas sociais vivenciados pelas mulheres em situação de tráfico de pessoas e migração irregular, está relacionado à precarização das relações de trabalho e à falta de políticas estatais efetivas. Reafirmam, portanto, que essa problemática deve ser estudada sob o horizonte das transformações societárias decorrentes do capital mundializado, principalmente no que diz respeito ao impacto sobre a vida das/os trabalhadoras e à feminização da pobreza, associando, óbvio, aspectos da estrutura de poder patriarcal que reproduz práticas que acentuam as diversas formas de violência contra as mulheres, exponenciando o preconceito e a xenofobia resultante da mobilidade fomentada pelas disparidades econômicas e sociais. Para a Política de Enfrentamento ao Tráfico de Pessoas ter efetividade no Ceará, é preciso decisão de governo e incorporação das ações e programas como uma política de Estado, articuladas com as demais políticas públicas, de forma a garantir a concepção multidimensional e intersetorial, fundantes nesse processo.

O compromisso pessoal com a temática e os arranjos institucionais que são realizados tem dado a tônica da política. Não desmerecemos as condições até agora garantidas; contudo, parte delas tem subsídio na esfera federal, o que demonstra ainda a não inserção efetiva da temática nas pautas dos governos estaduais e municipais. Associar a temática do tráfico de mulheres para fins de exploração sexual às questões mais estruturais da nossa sociedade não foi uma tarefa fácil em um universo de análises que tenta responsabilizar as mulheres individualmente ou idealizar condições de escolha em que, infelizmente, a realidade não se pauta. Por isso, confirmar que esse problema ainda não é enfrentado pelos governos com a seriedade necessária, provoca um sentimento de perplexidade e estarrecimento em um cenário donde reverberam e se amalgamam tensas zonas do sistema metabólico do capital, potencializado por desigualdades e paradoxos. Contudo, perceber o compromisso e o esforço pessoal e coletivo empregados por pessoas que estão buscando desenvolver ações nessa realidade adversa, motiva a somar energia nessa luta, que deve ser conjunta para a garantia da efetividade da política pública.

Sem pretensão de apontar respostas definitivas, nosso intuito foi provocar questionamentos que possam colaborar com a inquietude que o atual tempo histórico requer, afinal, como nos ensina Lukács (2007, p. 229), "não apenas a resposta, mas também as perguntas são produto imediato da consciência que guia a atividade". Desse modo, esperamos contribuir com a elaboração de perguntas que possam, em tempo futuro, desdobrarem-se em respostas coletivas pautadas em uma consciência revolucionária, mais particularmente a consciência militante feminista.

\section{Referências}

BRASIL. Ministério da Justiça. Convenção das Nações Unidas contra o Crime Organizado Transnacional (Convenção de Palermo) e leis nacionais. Brasília.

Ministério da Justiça. Plano Nacional de Enfrentamento ao Tráfico de Pessoas. Brasília: Ministério da Justiça, 2006.

Ministério da Justiça. Política Nacional de Enfrentamento ao Tráfico de Pessoas. Brasília: Ministério da Justiça, 2008.

Ministério da Justiça. Tráfico de pessoas para fins de exploração sexual e trabalho escravo. Brasília: OIT, 2005.

Secretaria Nacional de Justiça - Ministério da Justiça. Relatório Indícios de tráfico de pessoas no universo de deportadas e

não-admitidas que regressam ao Brasil via Aeroporto Internacional de Guarulhos. Brasília: Secretaria Nacional de Justiça, 2005. 
KEMPADOO, K. Mudando o debate sobre o tráfico de mulheres. Cadernos PAGU, n. 25, Campinas: Unicamp, 2005.

LUKÁCS, G. As bases ontológicas do pensamento e da atividade do homem. In: COUTINHO; NETTO (Orgs.). O Jovem Marx e outros escritos de filosofia. Rio de Janeiro: UFRJ, 2007.

MINAYO, M. C. S. O desafio do conhecimento científico: pesquisa qualitativa em saúde. São Paulo/Rio de Janeiro: Hucitec-Abrasco, 1993.

\section{Notas}

1 A investigação respeitou as normas éticas que regem a pesquisa científica com seres humanos, conforme Resolução 466/2012 do Conselho Nacional de Saúde (CNS), solicitando-se o consentimento livre e esclarecido das entrevistadas, bem como a autorização para realizar as observações e a preservação do anonimato das informantes. O projeto foi aprovado pelo Comitê de Ética em Pesquisa da Universidade Estadual doCeará.

2 Aprovada pelo Decreto N. 5.948, de 26 de outubro de 2006.

3 Decreto N. 30.682, de 22 de setembro de 2011, instituiu, no âmbito do Estado do Ceará, o Programa Estadual de Enfrentamento ao Tráfico de Pessoas, o Núcleo de Enfrentamento ao Tráfico de Pessoas (NETP), junto à Secretaria da Justiça e Cidadania (Sejus).

4 Rede Nacional de Núcleos e Posto de Referência e Atendimento às Vítimas do Tráfico de Pessoas, criada pela Portaria n. 41, de 6 novembro de 2009, que altera a Portaria n. 31 de 20 de agosto de 2009, que dispõe sobre Sistema Nacional de Referência e Atendimento às Vítimas do Tráfico de Pessoas e sobre as atribuições dos Núcleos de Enfrentamento ao Tráfico de Pessoas e dos Postos Avançados. Disponível em: http:// portal.mj.gov.br. Acesso em: 28 ago. 2013.

5 O Comitê Estadual Interinstitucional de Enfrentamento ao Tráfico de Pessoas foi instituído por meio do Decreto 30.682, de 22 de setembro de 2011. É a instância de monitoramento social do desenvolvimento das ações da Política Estadual de Enfrentamento ao Tráfico de Pessoas. Composto por 36 membros (titulares e suplentes), a saber: Gabinete do Governador, por meio da Coordenadoria de Políticas Públicas para as Mulheres; Secretaria da Justiçae Cidadania, que o preside; Secretaria de Trabalho e Desenvolvimento Social; Secretaria da Educação; Secretaria da Saúde; Secretaria da Segurança Pública e Defesa Social, com dois representantes, sendo um da Polícia Civil e outro da Polícia Militar; Magistratura Federal; Magistratura do Trabalho; Magistratura Estadual; Ministério Público Federal; Ministério Público do Trabalho; Ministério Público Estadual; Defensoria Pública da União; Defensoria Pública do Estado; Departamento de Polícia Federal; Departamento de Polícia Rodoviária Federal;Agência Brasileira de Inteligência.

6 Programa de Ações Integradas e Referenciais de Enfrentamento à Violência Sexual Infanto-Juvenil (PAIR), uma ação do Programa Nacional de Enfrentamento à Violência Sexual contra Criança eAdolescente da Secretaria de Direitos Humanos da Presidência da República (SEDH/PR). No Ceará, é realizado por meio da Secretaria do Trabalho e Desenvolvimento Social (STDS) e da Coordenadoria Especial de Políticas Públicas dos Direitos Humanos do Gabinete do Governador (COPDH).

7 A Secretaria da Justiça e Cidadania do Estado de Ceará criou em sua página na internet um acesso direto para denúncias.

8 Programa de Saúde da Família, vinculado à Rede de Atenção Básica em Saúde.

\section{Tatiana Raulino de Sousa}

tatianaraulino@yahoo.com.br

Doutoranda em Serviço Social pela Universidade do Estado do Rio de Janeiro (UERJ)

Professora do Curso de Serviço Social na Universidade Federal de Campina Grande (UFCG)

\section{UFCG}

Campus de Sousa - Centro de Ciências Jurídicas e Sociais

Rua Sinfrônio Nazaré, 38, Centro

Sousa - Paraíba - Brasil

CEP: 58800-240 